\title{
OSTEOSARCOMA IN PREGNANCY
}

\author{
Nepal P*, Singh G K*, Singh M P*, Bajracharya S*, Khanal G P, Pandey S R \\ * BP Koirala Institute of Health Sciences, Dharan, Nepal
}

\section{ABSTRACT}

Osteosarcoma in pregnant women is rare. Delay in diagnosis may be due to lack of any signs or symptoms during gestation, clinical misdiagnoses, religious attitude and refusal of the patients. Most cases soft-tissue and bone tumors during pregnancy can be managed successfully with surgery during gestation. Therapies with fetal toxicity were more likely to be deferred to postpartum period. This case is rare and liable to be missed, hence is reported.

\section{INTRODUCTION}

Osteosarcoma in pregnant women is rare and hence liable to be missed. ${ }^{1}$ The occurrence of cancer in a pregnant woman is an infrequent event, with an incidence of 0.07 to $0.1 \%$ of all pregnancies. ${ }^{1}$ However, there is no evidence of an increased incidence of cancers in pregnant women, nor any supporting data showing that pregnancy itself adversely affects the course of diseases. ${ }^{2}$ Delay in diagnosis may be due to lack of any signs or symptoms during gestation, clinical misdiagnoses, religious attitude and refusal of the patients. ${ }^{3}$ Whenever a pregnant woman is diagnosed as having malignant tumor serious medical, ethical, emotional, religious and philosophical problems arise.

\section{CASE REPORT}

A 25 year old $\mathrm{G}_{2} \mathrm{P}_{1} \mathrm{~L}_{1}$ at $38+{ }^{4 \mathrm{wks}}$ came to obstetrics department for elective caesarean section, and delivered a $3.2 \mathrm{Kg}$ male baby.
A swelling over the right lower end of femur and knee joint was noticed. Thinking it to be a knee effusion or phlegmasia alba dolens, orthopedic consultation was sought. On examination we found a swelling over the lower end of femur with dilated veins and shiny skin. The temperature was raised and the swelling measuring about $6 \times 4 \mathrm{~cm}$ with irregular margins, firm to hard in consistency and was fixed to the lower femoral metaphysis. The range of motion of the knee joint was normal. With a clinical diagnosis of a bony tumor, radiographs of the thigh with the knee joint Anteroposterior and Lateral views were taken. Radiographs showed features of osteosarcoma of the lower end of the femur (Figure 1). Similarly, radiograph of chest was done followed by ultrasonography of abdomen, which ruled out the evidence of metastasis. Core biopsy confirmed osteosarcoma (Figure 2). The tumor was graded according to Enneking's as Grade 2B. Limb salvage surgery (wide marginal resection with fibular grafting) was performed and patient was referred to cancer hospital for chemotherapy and radiotherapy.

\footnotetext{
Address for correspondence :

Dr. Pravin Nepal

BP Koirala Institute of Health Sciences, Dharan, Nepal

Email: pravinnnp@yahoo.com
}

Received Date : $2^{\text {nd }}$ May, 2005

Accepted Date : $15^{\text {th }}$ Aug, 2005 


\section{Fig. 1 : Showing AP and lateral radiograph of right lower end of femur.}

\section{DISCUSSION}

Osteosarcoma has already been described in pregnant woman. ${ }^{4,5,6}$ Huvos et al. reported 18 pregnant women in whom osteosarcoma were diagnosed during childbearing. Their ages ranged from 15 to 38 years. ${ }^{6}$ Osteogenicsarcoma occurred most frequently in the femur, followed by humerus and other sites. Maxwell et al. also reported osteosarcoma, chondrsarcoma and Giant-cell tumor of the extremity. The delayed in diagnosis may be due to lack of signs and symptoms, or suspicion of other plausible diagnosis specific to pregnancy. ${ }^{3}$ The treating physians also defers to get radiographs in the early stage due to fear of radiation hazard to the fetus. There are evidences of diagnosing the tumor during gestation or only after 3 months of delivery. ${ }^{1,3}$ These patients can be managed during pregnancy by performing limb-salvage surgeries based on Enneking's grading ${ }^{7}$ and chemotherapy which are not toxic to the fetus. Therapies with fetal toxicity were more likely to be deferred to the postpartum period. ${ }^{1}$ In disease with a favorable prognosis, treatment should be given as early as possible. The influence of pregnancy on the initiation, promotion and development of sarcomas is still controversial. ${ }^{3,6}$ Most of the full term babies are delivered normal but this cannot be guaranteed.
Fig. 2 : Showing features of Osteosarcoma.

\section{REFERENCES}

1. Maxwell C, Shah V, Wunder JS, Bell R, Farine D. Maternal and Neonatal outcomes in pregnancies complicated by bone and soft-tissue tumors. Obstetrics and Gynecology 2004; 104:344-348.

2. Doll DC, Scott Ringenberg Q, Yarbro JW. Antineoplastic agents and pregnancy. Semin Oncol1989; 16: 337-46.

3. Merimsky O, Cesne AL. Soft tissue and bone sarcomas in association with pregnancy. Acta Oncologia1998; 37:721-727.

4. Smith FR. The effect of pregnancy on malignant tumors. Am J Obstet Gynecol 1937; 34: 616-22

5. Pratt CB, Rivera G, Shanks E. Osteosarcoma during pregnancy. Obstet Gynecol 1977; 50:24.

6. Huvos AG, Butler A, Bretsky S. Ostegenic sarcoma in pregnant women. Cancer 1985; 56: 2326-31.

7. Enneking WF. A system of staging musculoskeletal neoplasms. Clin. Ortho. Related Research 1986; 204 : 9-24. 